\title{
Two QTL characterized for soft scald and soggy breakdown in apple (Malus $\times$ domestica) through pedigree-based analysis of a large population of interconnected families
}

\author{
Nicholas P. Howard ${ }^{1} \cdot$ Eric van de $\mathrm{Weg}^{2} \cdot$ John Tillman $^{1} \cdot$ Cindy B. S. Tong ${ }^{1} \cdot$ Kevin A. T. Silverstein ${ }^{3} \cdot$ James J. Luby $^{1}$
}

Received: 24 August 2017 / Revised: 23 November 2017 / Accepted: 27 November 2017 / Published online: 3 December 2017

(C) The Author(s) 2017. This article is an open access publication

\begin{abstract}
Soft scald and soggy breakdown are important postharvest physiological disorders of apple (Malus $\times$ domestica). 'Honeycrisp' and some of its offspring are particularly susceptible to developing these disorders. The purpose of this study was to identify molecular markers associated with high incidences of soft scald and soggy breakdown for use in marker-assisted breeding. Towards this aim, we employed a pedigree-based approach using mostly germplasm related to 'Honeycrisp.' Two quantitative trait loci (QTL) were consistently identified on linkage groups (LGs) 2 and 16 across the 2014 and 2015 harvest years. The same QTL were identified for both storage disorders, indicating that they may be physiologically related. 'Honeycrisp' is homozygous for an identical by state haplotype at the LG2 QTL that was consistently associated with a deleterious effect on soft scald and soggy breakdown incidence. This haplotype was traced through SNP-confirmed pedigrees to the following cultivars: 'Grimes Golden,' 'Northern Spy,' 'Rome Beauty,' and 'Fireside' and is common in derived apple germplasm. Haplotypes at the LG16 QTL could not be adequately characterized due to variation between years combined with effects of this QTL being of relatively smaller size and being most evident in individuals that carry two copies of the deleterious haplotype at the LG2 QTL. These results suggest that limiting homozygosity of the deleterious haplotype at the LG2 QTL through marker-assisted breeding would be a valid strategy to limit soft scald and soggy breakdown incidences in apple seedling populations.
\end{abstract}

Keywords Storage disorders $\cdot$ Marker-assisted breeding $\cdot$ FlexQTL ${ }^{\mathrm{TM}} \cdot$ PBA

\section{Introduction}

Soft scald (SS) and soggy breakdown (SBD) are economically significant cold storage disorders of apple (Malus $\times$ domestica) fruit. Fruits that develop either disorder are

Communicated by D. Chagné

Electronic supplementary material The online version of this article (https://doi.org/10.1007/s11295-017-1216-y) contains supplementary material, which is available to authorized users.

James J. Luby

lubyx001@umn.edu

1 Department of Horticultural Science, University of Minnesota, 342 Alderman Hall. 1970 Folwell Avenue, Saint Paul, MN 55108, USA

2 Plant Breeding, Wageningen University and Research, Wageningen, The Netherlands

3 Supercomputing Institute for Advanced Computational Research, University of Minnesota, St. Paul, MN, USA unmarketable for fresh eating. These disorders are problematic for growers because they usually develop weeks after producers have invested considerable resources into harvest and cold storage. Incidences of SS and SBD vary among cultivars. Soft scald, also known as ribbon scald, is characterized by distinct brown and often longitudinal lesions on the fruit that frequently extend into the flesh and can lead to secondary infections in the fruit (Brooks and Harley 1934; Meheriuk et al. 1994). Soft scald is said to be physiologically and incidentally distinct from the cold storage disorder superficial scald (Meheriuk et al. 1994; Kupferman 2001). SBD, also referred to as low-temperature breakdown (DeLong et al. 2004; Prange et al. 2011), is an internal disorder where the flesh of the fruit becomes brown, soft, spongy, and often moist (Plagge et al. 1935; DeLong et al. 2004). SBD is physiologically distinct from other forms of internal browning associated with cold storage, including senescent breakdown and $\mathrm{CO}_{2}$ injury (Brooks and Harley 1934; Prange et al. 2011; Watkins and Nock 2012). Soft scald and SBD may be physiologically 
related (Brooks and Harley 1934; Watkins and Rosenberger 2012; Watkins et al. 2004), though coincidence varies and some cultivars are only susceptible to either SS or SBD development (Brooks and Harley 1934; Watkins et al. 2005). Older literature lists several important cultivars as being susceptible to the development of SS and/or SBD, including 'Jonathan,' 'Winter Banana,' 'Northwestern Greening,' 'Rome Beauty,' 'Grimes Golden,' 'Golden Delicious,' 'Wealthy,' and 'Stayman Winesap' (Harley and Fisher 1931; Brooks and Harley 1934; Plagge and Maney 1937). More recent literature mentions 'Scifresh' as being susceptible to SS, but mostly focuses on 'Honeycrisp,' which is reported as being particularly susceptible to both SS and SBD (Rosenberger et al. 2001).

'Honeycrisp' has been very useful as a parent in apple breeding programs due to the exceptionally crisp texture of its fruit (Mann et al. 2005), which it retains through long periods of cold storage (Tong et al. 1999; Rosenberger et al. 2001, Trujillo et al. 2012), and its reported resistance to apple scab (Clark et al. 2014a). The usefulness of 'Honeycrisp' as a breeding parent warrants genetic studies designed to identify the presence of stable, large-effect quantitative trait loci (QTL) associated with the disorders, as well as the development of marker-assisted breeding (MAB) targets to select against the development of such storage disorders in future 'Honeycrisp' offspring.

Until recently, studies on SS and SBD have generally focused on identifying risk factors for these disorders, correlated variables, and management practices to reduce SS incidence, primarily in 'Honeycrisp.' These include studies investigating physiological differences between fruits affected and unaffected with SS (Hopkirk and Wills 1981; Tong et al. 2003; Johnston et al. 2009, 2010; Moran et al. 2009; EhsaniMoghaddam and DeEll 2013; Leisso et al. 2016) and/or SBD (Leisso et al. 2015), studies investigating differences in growing or harvesting conditions (Robinson and Watkins 2003; Watkins et al. 2005; Henriod et al. 2008; Johnston et al. 2009, 2010; Moran et al. 2009; Prange et al. 2011; Robinson and Lopez 2012), and studies investigating optimum storage conditions and treatments (Harley and Fisher 1931; Fan et al. 1999; Watkins and Rosenberger 2012; DeLong et al. 2004, 2006; Watkins et al. 2004; Johnston et al. 2009, 2010, Moran et al. 2010; Watkins and Nock 2012).

Although the previously cited studies are of great importance to postharvest physiologists and the commercial apple industry, they have provided limited insight for apple breeding efforts. At the time of this study, only two published studies have focused on evaluating the genetic basis of SS and/or SBD incidence. Alspach et al. (2000) reported high narrow-sense heritabilities for SS and low to medium narrow-sense heritabilities for "breakdown" and "chilling injury," respectively, suggesting genetic potential for limiting at least SS incidence in segregating families. More recently, McClure et al. (2016) reported on two QTL for SS incidence on linkage groups (LGs) 2 and 3 and on single SNP markers at each QTL where the heterozygous state was associated with higher SS incidence. Although these reports have provided useful and promising results, MAB targets for limiting SS and SBD incidence in progeny of 'Honeycrisp' based on consistent QTL results are still needed.

MAB targets for SS and SBD incidence will be most useful if they are compatible across a wide array of germplasm relevant to dessert apple breeding programs. Pedigree-based QTL analysis (PBA) (Van de Weg et al. 2003) using DNA markers, pedigree information, and inter-related populations has been proposed as an approach to identify and characterize more QTL and more alleles at identified QTLs than are possible in biparental QTL studies. Recent advances have been made in PBA by the development of dedicated software including FlexQTL ${ }^{\mathrm{TM}}$ (Bink et al. 2002, 2008, 2014; www.flexqtl.nl), Pedimap (Voorrips et al. 2012), and PediHaplotyper (Voorrips et al. 2016). PBA has been made a more attractive approach in apple through guidelines on the composition of the study germplasm (Peace et al. 2014), high throughput genomewide genotyping capabilities through SNP arrays (Chagné et al. 2012; Bianco et al. 2014, 2016), the availability of sets of pedigreed full-sib families (Peace et al. 2014), and standardized phenotyping procedures for some major traits (Evans et al. 2011a). This approach has been increasingly utilized in a variety of Rosaceous fruit species, including strawberry (Whitaker 2011; Roach et al. 2016; Mangandi et al. 2017), peach (Fresnedo-Ramírez et al. 2015, 2016; Mora et al. 2017), cherry (Rosyara et al. 2013; Stegmeir et al. 2014; Sandefur et al. 2016), and apple (Schmitz et al. 2013; Bink et al. 2014; Guan et al. 2015, Allard et al. 2016, Di Guardo et al. 2017; Durand et al. 2017).

The previously described techniques and tools should enable identification and characterization of QTL for SS and SBD incidence that can be used to aid in the development of MAB targets that are compatible across a diversity of germplasm important in apple breeding. With this context, the objectives of this study were to (1) identify QTL for SS and SBD incidence in pedigree-connected germplasm sets, (2) characterize the effects of functional haplotypes at identified QTL that are stable across both families and years, and (3) report on the composition of functional marker haplotypes in important cultivars and founding germplasm in a context appropriate for use in MAB. The ultimate goal of this study was to enable a MAB solution to developing apple populations and seedlings with lower incidences of SS and SBD.

\section{Materials and methods}

\section{Plant material}

The germplasm evaluated in this study included the University of Minnesota (UMN) portion of the RosBREED 
crop reference set (Peace et al. 2014), parental selections, and seedling families from the UMN apple breeding program, including four large full-sib families that share 'Honeycrisp' as the common parent (Table S1). Several small families were included in the analysis as the assumption was that they would share haplotypes with larger families at identified QTL based on pedigree-relatedness between families.

The non-'Honeycrisp' parents in the four large full-sib families were the UMN selection MN1702 and cultivars 'Jonafree,' 'Pitmaston Pineapple,' and 'Monark' as described in McKay et al. (2011). Most of the individuals from these four families also had an additional replicated tree that was also evaluated if fruit were available. A total of 433 individuals were evaluated between the two years of the study, which were all grown on 'Budagovsky 9' rootstock in Chanhassen, MN, USA, at the UMN Horticultural Research Center.

\section{Phenotypic data}

A minimum of 10 and a maximum of 25 fruit, depending on availability, were harvested from each tree when sampled fruits were at an estimated starch-iodine maturity rating of 5 or higher on the 8 point Cornell starch-iodine index (SI) scale (Blanpied and Silsby 1992). Reports of fruits with advanced maturity being more likely to develop SS (Harley and Fisher 1931; Brooks and Harley 1934; Meheriuk et al. 1994) with a reported maturity point of maximum susceptibility (Tomkins 1966; Prange et al. 2011), prompted us to use this intermediate to high SI maturity target rating rather than the SI maturity target rating of 3 that has been previously used in RosBREED phenotyping (Evans et al. 2011a). Fruit was evaluated for SI maturity rating following observations of skin background and over-color changes and the ease by which fruit released from the tree when picking. Fruits were harvested when their exterior was representative of most of the fruit on the tree and of the test fruit that had an SI rating of 5 or higher. In cases where fruit was limited, all fruit were harvested except for fruit that was clearly at a lower maturity level based on skin background and over-color.

Five of the harvested fruit were destructively evaluated at harvest to obtain an estimated average SI rating. All remaining fruit (16.5 fruit average between all individuals and replicated trees) were stored at $1{ }^{\circ} \mathrm{C}$ and evaluated for SS and SBD incidence after 20 weeks. Disorder incidence was recorded as the number of fruit with the disorder divided by the total number of fruit evaluated from a tree. Fruit were scored as having SS if they had symptoms consistent with the descriptions in Brooks and Harley (1934) and Meheriuk et al. (1994) of distinct brown, usually sunken, and often longitudinal lesions on the skin of the fruit appearing after a period of cold storage. Fruit were scored as having SBD if they had symptoms consistent with the description in Brooks and Harley (1934) of distinct brown and spongy tissue in the fruit cortex. The description and image of "low-temperature breakdown" provided in Meheriuk et al. (1994) was also used, but was modified for this study. Whereas the description in Meheriuk et al. (1994) noted that low-temperature breakdown is "usually... separated from the skin by normal tissue," fruit observed in this study with clear SBD symptoms in the presence of SS affected skin were scored as also having SBD. Examples of SS and SBD as defined in this study can be found in Fig. S1. Fruit that were too damaged or rotted to evaluate were excluded from analysis.

Statistical correlations were evaluated between SS and SBD incidence for 2014 and 2015 and between disorder incidence and average SI rating at harvest. Since the distribution of disorder incidence departed greatly from normal, these correlations were calculated using the non-parametric Kendall's tau-b coefficient by means of the Kendall package (McLeod 2011) in the statistical software $\mathrm{R}$ version 3.3.0 ( $\mathrm{R}$ Core Team 2017). All pair-wise comparisons that were found to be statistically significant in this test were also checked for statistical significance when applying a Bonferonni correction to account for multiple comparisons.

\section{Genetic data}

All individuals were genotyped on the International RosBREED SNP Consortium 8K Illumina Infinium ${ }^{\circledR}$ array v1 (Chagné et al. 2012) with the exception of several founding genotypes or intermediate ancestors, whose genetic data were provided by FruitBreedomics (Laurens et al. 2010) and were genotyped on the Illumina Infinium ${ }^{\circledR}$ 20K array (Bianco et al. 2014). The DNA extraction methods used were as in Clark et al. (2014b). Genotype data for the four large full-sib families came from a previous study on the creation of an integrated genetic map (Howard et al. 2017). SNP alleles for the remaining germplasm were called together using automated allele calling in GenomeStudio ${ }^{\mathrm{TM}}$. Marker data were evaluated for consistency within pedigrees with the assistance of the marker evaluation functions of FlexQTL ${ }^{\mathrm{TM}}$ and Visual FlexQTL ${ }^{\mathrm{TM}}$. Missing data were inferred by FlexQTL ${ }^{\mathrm{TM}}$ where feasible. Suspected false or questionable recombinations were evaluated, and genotype scores were changed or recoded as missing data if it was evident that an individual had a genotype score that could not have been inherited or passed on to offspring given information from the connected pedigree. All pedigree relationships used in this study have been validated through SNP data using a process similar to that used in Howard et al. (2017) to confirm ancestors of 'Honeycrisp.' A total of 3419 SNPs were used in the QTL analyses. The genetic map used in this study is described in Howard et al. (2017). The marker data for seedling individuals evaluated in this study can be found in Table S2. 


\section{QTL analyses}

FlexQTL ${ }^{\mathrm{TM}}$ software (www.flexqtl.nl) was used to conduct the QTL analyses. The Bayesian statistics and PBA methodology used in FlexQTLTM, as described in Bink et al. $(2002,2008,2012)$ built from approaches and procedures developed in Sillanpää and Arjas (1999). The implementation of FlexQTL ${ }^{\mathrm{TM}}$ in QTL analyses has been described in detail in Bink et al. (2014) in a proof of concept paper. Each separate QTL analysis had Markov chain Monte Carlo simulation lengths of $2.5^{*} 10^{5}$, with every 250th sample stored for a total of 1000 samples for use in posterior QTL inferences. Additional duplicate QTL analyses were performed with two different starting seed numbers, maximQTL settings $(5,10)$, and priorQTL settings $(2,5)$ for the Markov chain Monte Carlo simulation for each year-trait combination evaluated in order to ensure the results for the identified QTL, and their positions were reproducible. Data from only one simulation from each year and trait combination is reported in this paper, with the following settings: maximQTL $=5$, priorQTL $=2$, addGENE $=5$ (for QTL effects being additive with a normal prior distribution and a (co)variance matrix with a random, diagonal structure). QTL positions were recorded as QTL intensity estimates via posterior distributions of QTL locations as described in Sillanpää and Arjas (1999). QTL regions were recorded as a series of successive 2-cM bins with $2 * \ln$ Bayes factors (Kass and Raftery 1995) that were greater than 5. The most probable QTL positions were recorded as the median $\mathrm{cM}$ value from the Markov chain Monte Carlo simulation samples within each QTL region.

Separate QTL analyses were performed for both SS and SBD incidences for 2014 and 2015. Phenotypic scores for individuals with replicates were averaged for the purposes of QTL analyses. Physical locations for identified QTL that were consistent across years were retrieved by blasting SNP sequences at QTL regions to version 1.1 of the GDDH13 apple reference genome (Daccord et al. 2017, https://iris.angers.inra. fr/gddh13/) with BLASTN 2.2.25+ (Zhang et al. 2000).

\section{Haplotype analysis}

QTL that were consistently identified in both 2014 and 2015 with $2 \operatorname{lnBF}>5$, indicating at least strong evidence for QTL (Bink et al. 2008), were considered for haplotype analysis. Marker phasing was conducted using FlexQTL ${ }^{\mathrm{TM}}$. Fifteen successive SNP markers were chosen for marker haplotyping of each QTL region based on their proximity to identified QTL peaks. Haplotype identities were assigned by marker state (Identity by state, IBS), but also traced through known pedigrees (Identity by descent, IBD) to ensure marker data and phasing were consistent across connected pedigrees. Genome-wide phased marker data for parents that did not have SNP-confirmed pedigrees were compared to founder genotypes that had the same haplotype at QTL of interest to determine whether it is likely that important haplotypes may also be IBD via distant, but still unidentified genetic relationships. Haplotypes that were identical by state (IBS) between these parents and founders were considered likely to be IBD if they shared multiple extended IBS haplotypes of more than $10 \mathrm{cM}$ that together totaled more than $10 \%$ of the SNP genome from the linkage map used in this study, which is more than $234.4 \mathrm{cM}(=10 \% \times 1172 \mathrm{cM}($ Howard et al. 2017$) \times 2$ parental haplotypes for diploids). These postulated relationships also had to be temporally and geographically consistent with available historical information about the listed pedigree for the parent under consideration.

Bootstrapping was used to estimate SS and SBD incidence means and $95 \%$ confidence intervals per year for individuals grouped by their haplotype composition at underlying identified QTL using R (R Core Team 2017) to estimate the effects of functional haplotypes. Mean disorder incidence and $95 \%$ confidence intervals for each defined haplotype group were generated from 10,000 bootstrap sample means. Each bootstrap mean was comprised of $N$ observations of disorder incidence with replacement, where $N$ was equal to the number of genetically distinct individuals in the dataset from which bootstrap statistics were being generated. The replicates for individuals were weighted, meaning both of the disorder incidence observations for an individual with a replicate were individually half as likely to be chosen at random for inclusion into a single bootstrap sample mean compared to an individual that did not have a replicate. Conclusions regarding haplotype effects were based on differences between mean disorder incidences and associated $95 \%$ confidence intervals of the defined haplotype groups, without correction for multiple comparisons. This method was used because of the non-normal distribution of the phenotypic data and to incorporate the uneven replication in the populations that were evaluated.

\section{Results}

\section{Phenotypic data}

SS and SBD incidences ranged from either extreme, were heavily skewed towards no incidence (Figs. S2 and S3), and showed modest but significant year-to-year correlations $(\tau-$ $b^{2}=0.23$ and 0.18 for SS and SBD, respectively) (Table S3; Fig. S4). Coincidence of SS and SBD within individuals was very high for both years studied $\left(\tau-b^{2}=0.53\right.$ and 0.64 for 2014 and 2015, respectively) (Table S3), though many individuals had separate fruit with only either SS or SBD. Average SI rating at harvest ranged from either extreme on the 8-point Cornell SI scale (Fig. S5) despite the target SI rating of 5. SI was not correlated with either SS or SBD with the exception of 
a weak, positive correlation between SI and SS in $2014(P=$ 0.047). (Table S3).

\section{QTL discovery}

Two QTL were consistently identified in separate analyses of both SS and SBD in both 2014 and 2015 at the top of LG2 and the middle of LG16 (Tables 1 and 2; Fig. 1). The only other genome region with strong evidence $(2 \operatorname{lnBF}>5)$ for the presence of a QTL was on LG13 for SS in 2014 (Tables 1 and 2). The LG2 QTL spans the physical range of approximately 0.2 to $1.5 \mathrm{Mbp}$ (SNPs ss475876955 to ss475876990), indicating that the QTL is at the top of chromosome 2. The LG16 QTL spans the physical range from approximately 11.5 to 12.3 Mbp (SNPs ss475881829 to ss475881842). Use of binary data rather than original incidences resulted in the identification of the same QTLs (data not shown).

\section{Haplotype analyses at LG2 QTL}

At the LG2 QTL, 19 haplotypes were represented in the parents of seedling families using 15 markers between 0 and $2.03 \mathrm{cM}$ (Tables S4 and S5). One haplotype was consistently associated with increased incidence of SS and SBD and will be referred to as the high disorder incidence (HDI) haplotype. 'Honeycrisp' is homozygous for the HDI haplotype. In the three larger 'Honeycrisp' families where the other parent is heterozygous for the HDI haplotype, homozygous HDI offspring exhibited consistently higher incidences of both SS and SBD than offspring with only one HDI haplotype in both 2014 and 2015 (Fig. 2). None of the larger families in the study were derived from two heterozygous HDI parents, resulting in an absence of offspring that had no copies of the HDI haplotype. However, such progenies did occur with some of the smaller families. The general trend across the entire population for SS and SBD incidence versus the number of HDI haplotypes in individuals was that the effect of a second copy was about 2 to 6 times higher than that of a single copy in 2014 and 2015, respectively (Fig. 3). This trend was consistent for both disorders and implies that the LG2 QTL showed

Table 1 Bayes factors $(2 * \ln )$ for a 1 QTL versus 0 QTL model per linkage group for soft scald and soggy breakdown incidence for all years evaluated in this study. The $2 * \ln$ Bayes factors are interpreted as having very little (0-2), positive (2-5), strong (5-10), and decisive (> 10)
Table 2 QTL regions and peak positions for soft scald and soggy breakdown for QTL with $2 * \ln$ Bayes factors greater than 5 . QTL regions reported consist of successive 2 -cM bins with $2 * \ln$ Bayes factors greater than 5. QTL peaks were recorded as the median $\mathrm{cM}$ value from the Markov chain Monte Carlo simulation samples within the QTL regions

\begin{tabular}{llccc}
\hline LG & Trait & Year & QTL region $(\mathrm{cM})$ & QTL peak (cM) \\
\hline 2 & \multirow{2}{*}{ Soft scald } & 2014 & $0-8$ & 2.8 \\
& & 2015 & $0-4$ & 1.2 \\
& \multirow{2}{*}{ Soggy breakdown } & 2014 & $0-4$ & 2.3 \\
& & 2015 & $0-4$ & 1.3 \\
13 & \multirow{2}{*}{ Soft scald } & 2014 & $34-36$ & 34.9 \\
16 & Soft scald & 2014 & $24-38$ & 30.8 \\
& & 2015 & $32-42$ & 35.8 \\
& \multirow{2}{*}{ Soggy breakdown } & 2014 & $34-40$ & 37.5 \\
& & 2015 & $32-38$ & 35.1 \\
\hline
\end{tabular}

partial negative dominance when this QTL is examined on its own. Averaged over disorders, years, and LG16 QTL genotypes, incidence decreased from 0.43 , to 0.14 , and to 0.07 for individuals having two copies, one copy, and no copies of the HDI haplotype, respectively.

\section{Haplotype analyses at LG16}

The LG16 QTL had 16 haplotypes represented in parents of the seedling families using 15 markers between 34.2 and $37.6 \mathrm{cM}$ (Tables S5 and S6). Some haplotypes at the LG16 QTL were associated with greatly increased SS and SBD incidence in three of the large 'Honeycrisp' families, though these effects were not as large as the HDI haplotype at the LG2 QTL. The LG16-H03 haplotype showed variable performance among families. It was associated with increased incidence in the 'Honeycrisp' $x$ 'Monark' family but not in the 'Honeycrisp' x MN1702 family. In the 'Jonafree' $x$ 'Honeycrisp' family, haplotype effects were inconsistent between years, but the LG16-H08 haplotype was associated with higher disorder incidence in 2015. No haplotypes from the smaller families were identified that were associated with high

evidence for a 1 QTL model versus a 0 QTL model per linkage group. The shade of red corresponds to the height of the observed $2 \operatorname{lnBFs}$ ranging from white $(2 \operatorname{lnBF}=-3)$ to deep red $(2 \operatorname{lnBF}=18)$

\begin{tabular}{|c|c|c|c|c|c|c|c|c|c|c|c|c|c|c|c|c|c|c|}
\hline \multirow[t]{2}{*}{ Trait } & \multirow[t]{2}{*}{ Year } & \multicolumn{17}{|c|}{ Linkage group } \\
\hline & & 1 & 2 & 3 & 4 & 5 & 6 & 7 & 8 & 9 & 10 & 11 & 12 & 13 & 14 & 15 & 16 & 17 \\
\hline \multirow[t]{2}{*}{ Soft scald } & 2014 & -2.3 & 14 & -0.3 & -0.8 & -0.4 & -1.4 & -1.5 & -2.1 & 2.6 & -1 & -0.6 & -2.1 & 5.2 & -2.2 & 0.3 & 13 & 0.1 \\
\hline & 2015 & 0.2 & 18 & 0.2 & -1.9 & -2.3 & 0.5 & -2.1 & 1.9 & -0.8 & 0.9 & -3 & -1.9 & -0.6 & -1.5 & -1.1 & 6.7 & -2.4 \\
\hline \multirow[t]{2}{*}{ Soggy breakdown } & 2014 & -2.1 & 9.2 & 1.3 & -2 & -1.3 & -1.2 & -2.3 & -1.3 & -0.1 & -1.5 & -1.9 & -2.2 & 2.3 & -2 & 0.2 & 9.1 & -1.2 \\
\hline & 2015 & 0.5 & 18 & -0.9 & -1.8 & -2.3 & -0.1 & -1.7 & -0.5 & 0.7 & -0.9 & -2.7 & -0.9 & -1 & 0 & 0.1 & 11 & -2.5 \\
\hline
\end{tabular}




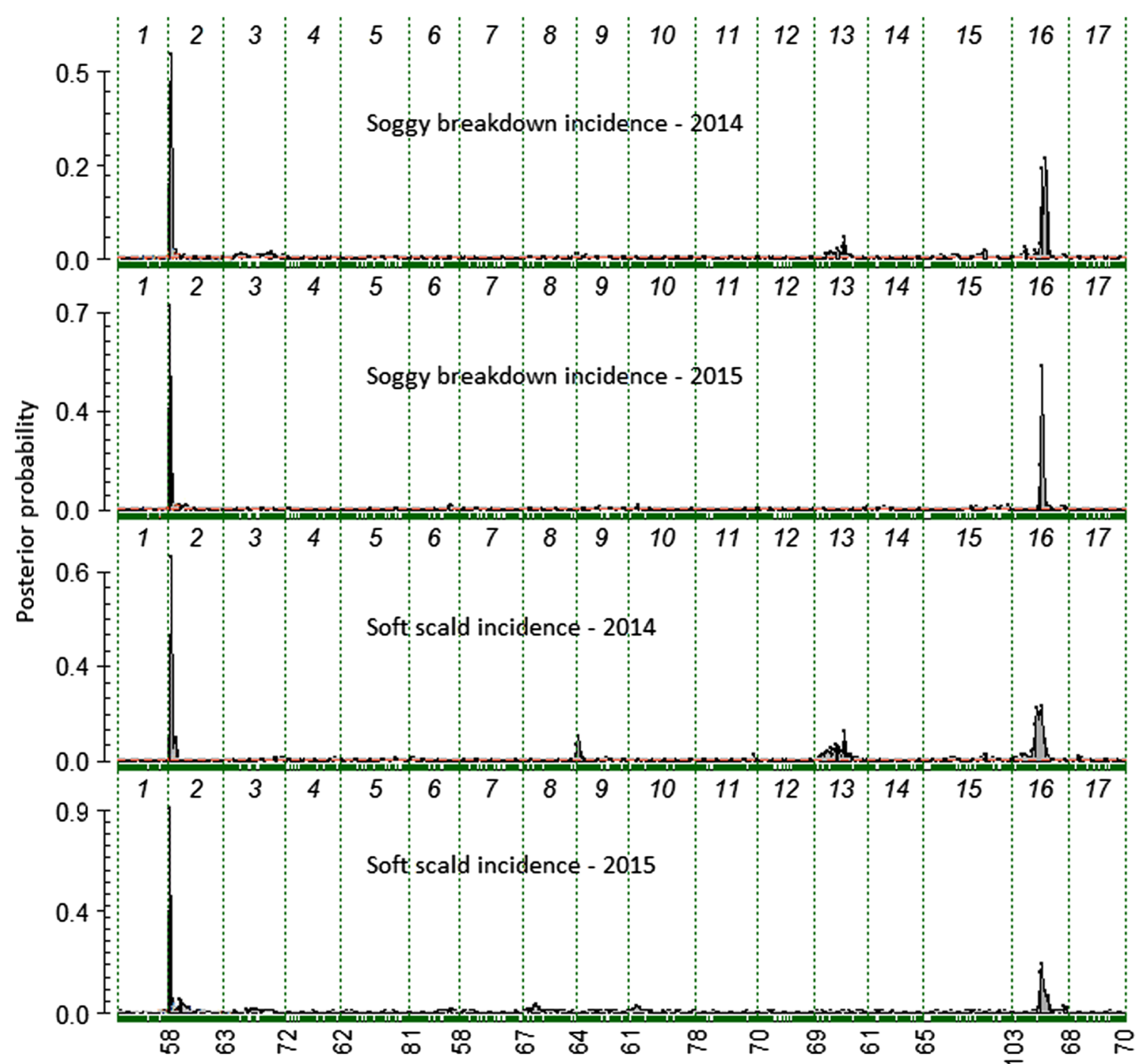

Fig. 1 Posterior probability for QTL positions from FlexQTL output for soft scald and soggy breakdown incidence in 2014 and 2015. Chromosome numbers are indicated at the top of each graph. Green

disorder incidence, and there were no differences in disorder incidences observed between either haplotype from 'Honeycrisp' at this QTL (data not shown).

\section{Interaction between LG2 and LG16 QTL}

Considering the compound LG2/LG16 QTL genotypes (Fig. 4), the three larger 'Honeycrisp' families showed a consistent pattern across both disorders and across years for the HDI homozygous, but not for the HDI heterozygous offspring. The 'Honeycrisp' $x$ MN1702 family was the only family that showed a consistent pattern both across years and HDI dose, whereby the LG16-H03 $3_{\text {Fireside }}$ haplotype was always associated with low disorder incidences. Also, the LG16-H07 haplotype was only associated with higher disorder incidences with two copies of the HDI haplotype at the LG2 QTL (Fig. 4). The latter, if reproducible, would indicate lines at the bottom of each graph indicate marker positions. Numbers below the series of graphs indicate the $\mathrm{cM}$ position at the end of each linkage group

that the LG2 QTL is epistatic to the LG16 QTL in the 'Honeycrisp' $x$ MN1702 family, whereby the LG16$\mathrm{H} 03_{\text {Fireside }}$ haplotype comes only to expression in conjunction with two HDI doses at LG2. The 'Honeycrisp' $x$ 'Monark' family showed a consistent pattern for the HDI-homozygous offspring, whereby the LG16-H03 $3_{\text {Monark }}$ haplotype was associated with high disorder incidence and the LG16-H06 haplotype was associated with a moderate incidence. Low disorder incidence was observed in individuals from this family with a single HDI dose, with the exception of the LG16-H03 ${ }_{\text {Monark }}$ haplotype in 2014, which was associated with moderate disorder incidence. The 'Honeycrisp' $\mathrm{x}$ 'Jonafree' family was variable in SS and SBD incidences across all QTL genotypes and years. In 2014, the mean disorder incidence of each of the four compound QTL genotypes was similar with large 95\% confidence intervals. However, in 2015, the LG16-H08 was associated with higher disorder incidences compared to the 


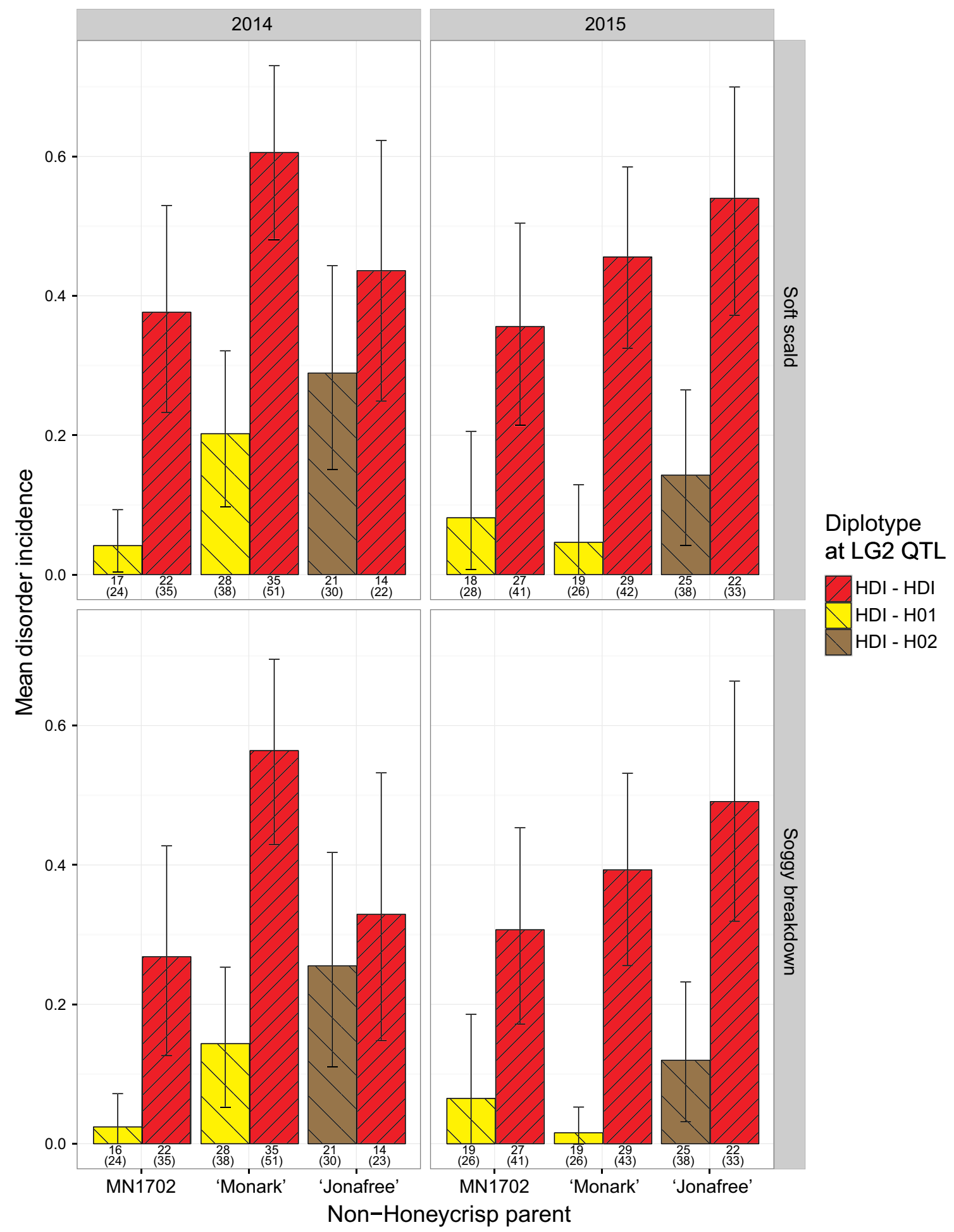

Fig. 2 Mean incidences and their 95\% confidence intervals for soft scald and soggy breakdown in 2014 and 2015 for offspring from three families segregating for number of copies of the high disorder incidence (HDI) haplotype grouped by family and diplotype at the LG2 QTL

(bootstrapped data). Numbers below bars represent the number of individuals within each category with the number in parentheses representing the number of individuals and their replicates

LG16-H04 haplotype when in conjunction with a single HDI dose, and both haplotypes were associated with relatively higher disorder incidences in conjunction with two copies of the HDI haplotype at the LG2 QTL versus only one copy of the HDI haplotype. The variable performance of this QTL over years and genetic backgrounds hampered summarizing 
Fig. 3 Mean incidence and 95\% confidence intervals for soft scald and soggy breakdown in 2014 and 2015 for offspring across all families grouped by number of the high disorder incidence (HDI) haplotype at the LG2 QTL (bootstrapped data). Numbers below bars represent the number of individuals within each category with the number in parentheses representing the number of individuals and their replicates

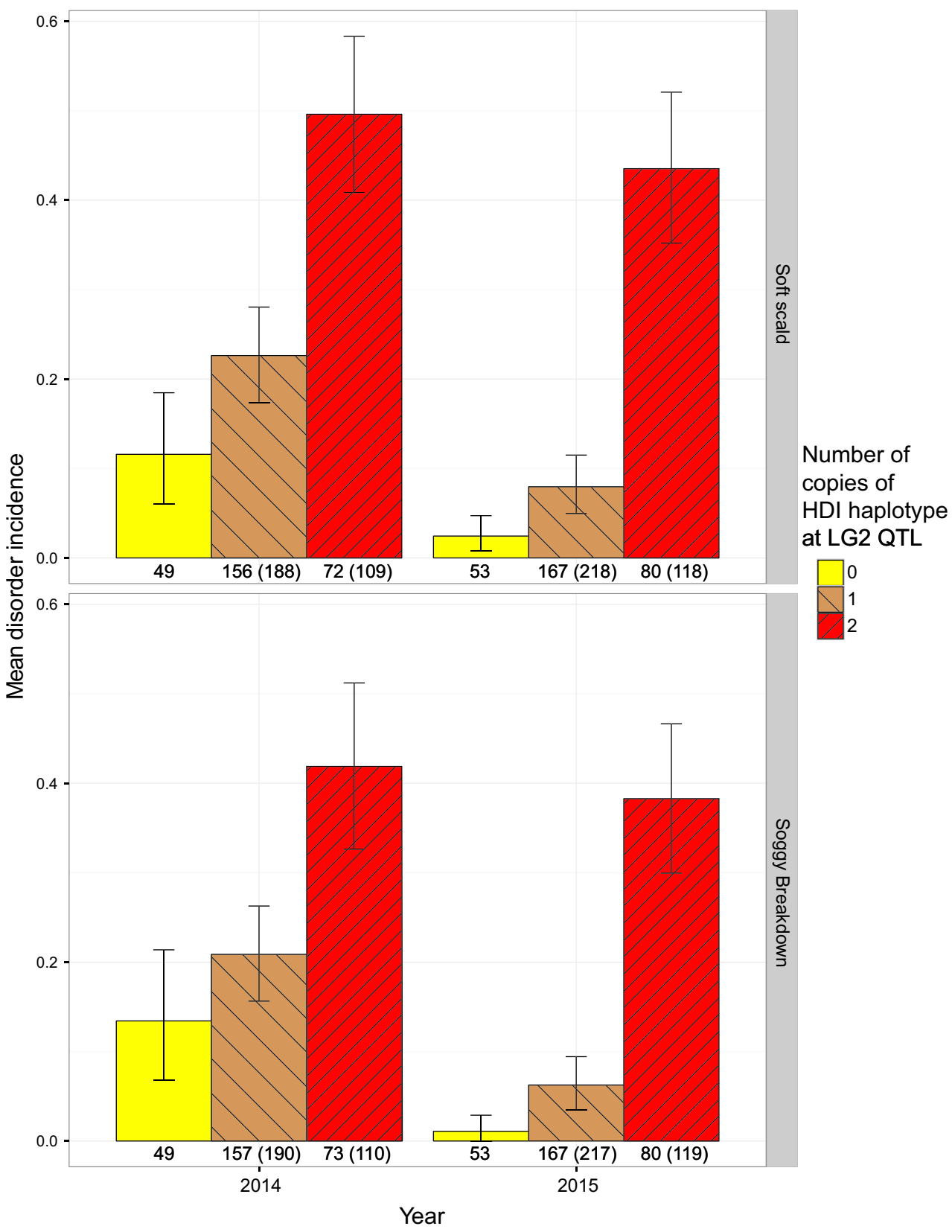

the effect of this QTL by a simple, single quantification, as was possible with the LG2 QTL.

\section{Origin of LG2 high disorder incidence haplotype}

The origin of the HDI haplotypes in 'Honeycrisp' were traced to 'Northern Spy' through parent 'Keepsake,' and 'Grimes Golden' through parent MN1627 (Howard et al. 2017) (Table S4). Multiple parents of families evaluated in this study share one copy of the HDI haplotype by descent (Table S4). 'Honeygold' inherited it from its grandparent 'Grimes Golden' through 'Golden Delicious,' and 'Sweet 16' inherited it from its parent 'Northern Spy.' MN1702 and 'Wildung' both inherited this haplotype from 'Fireside.' 'Jonafree,' 'Dayton,' and 'Monark' did not have their direct parents genotyped with the array. The origin of their HDI haplotypes could be deduced by comparing their phased SNP data to the phased SNP data for earlier ancestors or, in the case of 'Monark,' to likely founding cultivars, as detailed below.

The pedigree of 'Jonafree' has been published (Dayton et al. 1979), and marker data were available for three of its grandparents and both of its great- grandparents through the grandparent that did not have marker data available. 'Jonafree' likely inherited its copy of the HDI haplotype through its ungenotyped parent NJ31 from either grandparent 'Rome Beauty' or 'Northern Spy' as it could not have inherited its 
other haplotype (LG2-H02) from either of these grandparents. The LG2 homolog in 'Jonafree' containing the HDI haplotype is IBS with 'Rome Beauty' for the first 49 cM of LG2 (155 markers). After this point, the haplotype matches with 'Northern Spy' for the remainder of the chromosome, indicating a meiotic recombination event at $49 \mathrm{cM}$ in the gamete from NJ31 that formed 'Jonafree.' For the HDI haplotype to have been inherited through 'Northern Spy,' a recombination would have been necessary at $2 \mathrm{cM}$ and again at $49 \mathrm{cM}$ within NJ31 between its 'Northern Spy' and 'Rome Beauty' LG2 homolog. Either source was considered possible (Table S4).

The published pedigree of 'Dayton' (Korban et al. 1988) matched with SSR marker genotypes of 'Dayton' and its contributing founders when its assumed great- grandparent 'Jonathan' would be replaced by 'Golden Delicious' (Evans et al. 2011b). Extended SNP haplotypes shared between 'Dayton' and 'Golden Delicious' for at least $10 \mathrm{cM}$ span $612 \mathrm{cM}$, or $26 \%$, of their phased marker data and include five regions larger than $30 \mathrm{cM}$. 'Rome Beauty' and its sport 'Red Rome' are validated founders for 'Dayton' in different areas of the pedigree as a great-grandparent, a great-great-grandparent, and as two great-great-great-grandparents (coefficient of relationship $=0.25$ ). Extended SNP haplotypes shared between 'Dayton' and 'Rome Beauty' for at least $10 \mathrm{cM}$ span $611 \mathrm{cM}$, or $26 \%$, of their phased marker data and include five regions larger than $30 \mathrm{cM}$. 'Rome Beauty' is the likely source of the HDI haplotype as the first $\sim 12.9 \mathrm{cM}$ (81 markers) of 'Dayton' match with 'Rome Beauty,' though it is also possible that 'Golden Delicious' could have contributed the HDI haplotype instead, with evidence of meiosis being undetected due to having a common extended haplotype with 'Rome Beauty' for the first $2.03 \mathrm{cM}$ of the linkage map. Furthermore, the individuals in the published pedigree of 'Dayton' (Korban et al. 1988), 'Wealthy,' 'Melba,' 'Jonathan,' 'Starr,' and $F_{2}$ 26829-2-2, do not have the HDI haplotype (Table S4).

'Monark' (also known as AA-44) was developed by the University of Arkansas and recorded as being the offspring of a cross between NJ674016 and NJ40 (Rom et al. 1998). No pedigree data were available for these selections, but the selection designation indicated they were from Rutgers University as part of the cooperative apple breeding program of Purdue University, Rutgers University, and the University of Illinois, which extensively used both 'Golden Delicious' and 'Rome Beauty' in crosses (Crosby et al. 1990). Extended SNP haplotypes longer than $10 \mathrm{cM}$ shared between 'Rome Beauty' and 'Monark' span $19.8 \%$ of their phased marker data and include one region of $33.8 \mathrm{cM}$. Extended SNP haplotypes longer than $10 \mathrm{cM}$ shared between 'Golden Delicious' and 'Monark' span $28 \%$ of their phased marker data and include five regions that are greater than $30 \mathrm{cM}$. The first $13.1 \mathrm{cM}$ ( 89 markers) of LG2 containing the HDI haplotype for 'Monark' is IBS with 'Golden Delicious' and 'Grimes Golden,' compared to only $5 \mathrm{cM}$ with 'Rome
Beauty,' indicating it is likely that 'Monark' inherited its copy of the HDI haplotype from 'Golden Delicious.'

\section{Origin of the LG16 haplotypes for high disorder incidence}

The LG16-H07 haplotype in MN1702 associated with increased SS and SBD incidences (Fig. 4) in the 'Honeycrisp' $\mathrm{x}$ MN1702 family was inherited from its parent 'Frostbite' (Table S6). The other haplotype in MN1702 (LG16-H03) was inherited from its other parent 'Fireside' (Table S6) and is IBS to the haplotype from 'Monark' that was associated with increased SS and SBD incidences in the 'Honeycrisp' $x$ 'Monark' family (Fig. 4). As the two LG16-H03 haplotypes were associated with distinct disorder incidence levels, we differentiated them by their ancestral origin ( $\mathrm{H} 03_{\text {Fireside }}$ and $\left.\mathrm{H} 03_{\text {Monark }}\right)$, whereby the sources of the LG16 haplotypes in 'Monark' were unable to be determined.

\section{Discussion}

We identified QTL for SS (soft scald) and SBD (soggy breakdown) incidence on LGs 2 and 16 in two years of observation (Tables 1 and 2) across a pedigree-connected germplasm set. SNPs flanking these QTL peaks were located at the top of chromosome 2, and middle of LG16. The observed concordance of these two storage disorders and characteristics of the discovered QTLs will be discussed below.

\section{Relationships between SS and SBD}

SS and SBD incidences were significantly correlated in this study (Table S3). This is consistent with hypotheses from some earlier studies that these disorders might be physiologically related (Brooks and Harley 1934; Watkins and Rosenberger 2012; Watkins et al. 2004). These previous studies evaluated the disorders only within individual cultivars. In contrast, our study identified a correlation between SS and SBD across segregating full-sib families. Additionally, SS and SBD were often observed in separate fruits from the same individual. These observations, in conjunction with the consistent identification of both the QTL on LGs 2 and 16 using phenotype data from either disorder, support the hypothesis that these disorders are related physiologically and genetically.

\section{Previously reported QTL for SS and SBD}

At the time of our study, only one other QTL study for SS incidence and no QTL studies for SBD incidence have been published. A QTL for SS incidence on LG2 has been reported in a ('Summerred' x 'Discovery') x ('Splendor' x 'Gala') family evaluated in Canada (McClure et al. 2016). Its QTL peak was at 


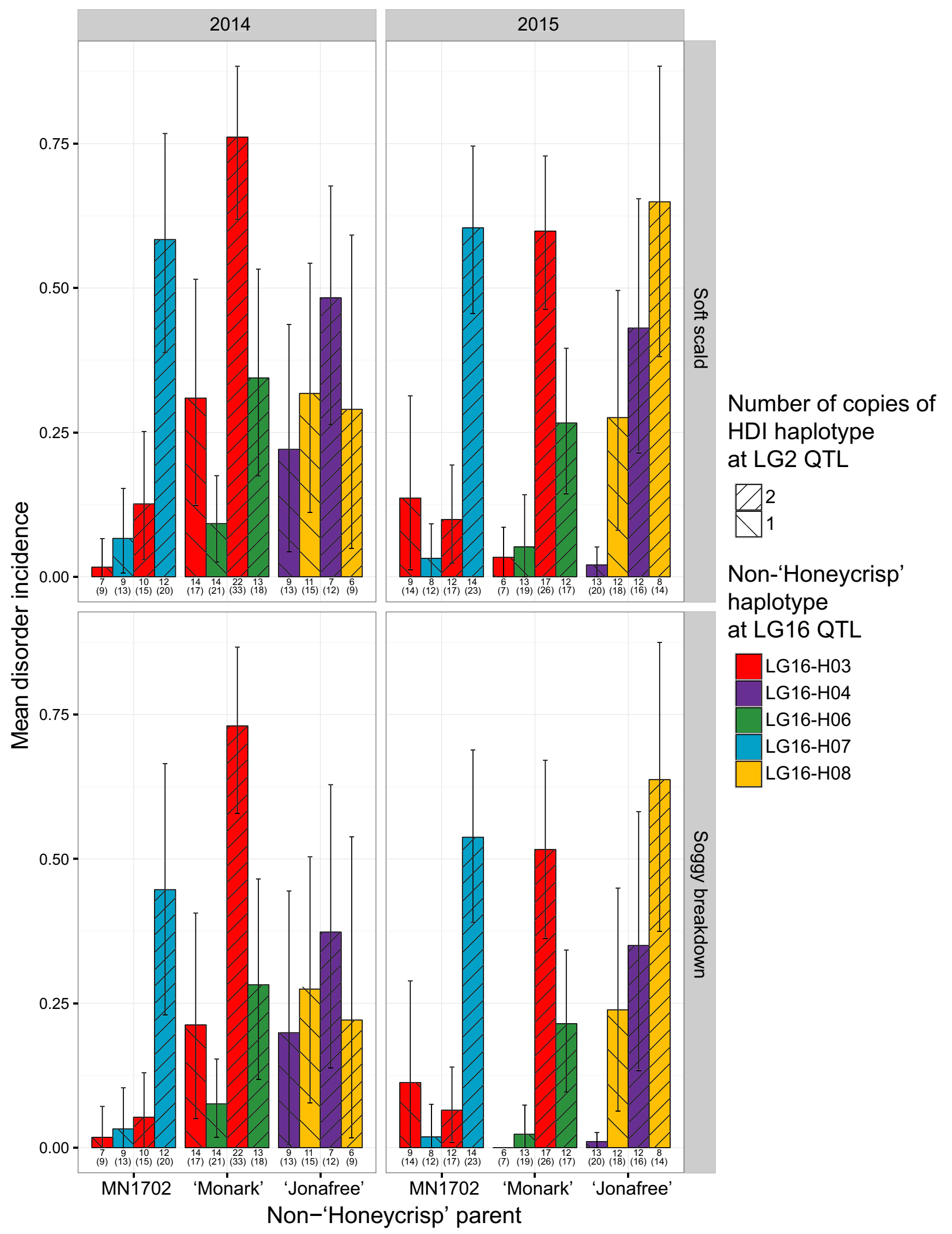


Fig. 4 Mean incidence and 95\% confidence intervals for soft scald and soggy breakdown in 2014 and 2015 for offspring from three families with 'Honeycrisp' as a common parent across all germplasm evaluated, grouped by number of copies of the high disorder incidence (HDI) haplotype at the LG2 QTL and the non-'Honeycrisp' haplotype contribution at the LG16 QTL (bootstrapped data). Note that the LG16-H03 haplotype could not be traced to the same ancestral origins between MN1702 and 'Monark.' Numbers below bars represent the number of individuals within each category with the number in parentheses representing the number of individuals and their replicates

a genotype-by-sequencing SNP at the physical position of 3,379,607 bp of version 1.0 of the Golden Delicious reference genome (Velasco et al. 2010; McClure et al. 2016), which is located between SNPs at 4.21 and $5.33 \mathrm{cM}$ in the map used in this study. This places the McClure et al. (2016) LG2 QTL peak between 1.45 and $4.17 \mathrm{cM}$ away from the QTL peaks for SS incidence identified in our study, suggesting that they are the same QTL and that this QTL is expressed and relevant across multiple locations and populations.

SNP array data were not available for the parents in the McClure et al. (2016) cross where the LG2 QTL was identified; however, SNP array data were available for all four grandparents. None of these grandparents carry a copy of the HDI haplotype, indicating that additional haplotypes from different backgrounds may be associated with higher SS incidence at this QTL. The McClure et al. (2016) study also evaluated a 'Honeycrisp' $\mathrm{x}$ 'Ambrosia' cross. This cross segregates for one and two copies of the HDI haplotype as 'Ambrosia' has one copy of the HDI haplotype from 'Grimes Golden' through parent 'Golden Delicious.' However, no QTL were identified from this cross with the explanation provided being that small population size and GxE interactions may be to blame.

\section{Fine mapping of and candidate genes for the LG2 QTL}

Despite significant consistency in disorder incidence observed between 2014 and 2015 (Table S3) and the consistently identified position of the LG2 QTL for both disorders (Tables 1 and 2 ; ), the quality of the phenotypic data limited our ability to accurately fine map this QTL to an interval of less than $4 \mathrm{cM}$. This is possibly due to the small effective size of our study population, possible variable environmental effects on incidences of SS and SBD (as reflected by the observed moderate correlations between years), negative dominance at the LG2 QTL and/or the interaction with the second QTL identified on LG16, and other background genetic effects. However, markers for the identified founding sources of the HDI haplotype at LG2 are identical in state for a set of 21 SNP markers covering the first $2.03 \mathrm{cM}$ of the linkage map. This area contains QTL identified for various alcohols and esters (Dunemann et al. 2009; Souleyre et al. 2014; Farneti et al. 2017) and aromatic compounds (Souleyre et al. 2014; Kumar et al. 2015; Yauk et al. 2015; Farneti et al. 2017) found in fruit that were thought to be under regulation of $M d A A T 1$ (MDP0000637737) (Souleyre et al. 2014; Farneti et al. 2017), which codes for an alcohol acyl-transferase that catalyzes the transacylation from acyl-CoA to alcohol (Souleyre et al. 2005), the suppression of which led to increased levels of hexanol and other alcohols (Souleyre et al. 2014). MdAAT1 is within the LG2 QTL identified in this study. A series of publications from the 1970s reported that exposing or injecting 'Jonathan' fruit with hexanol or hexyl acetate resulted in the formation of SS (Wills and Scott 1970; Wills 1972, 1973). Additionally, Leisso et al. (2016) observed that higher levels of hexanol were associated with increased risk of soft scald formation in 'Honeycrisp' apples. Taken in the context of the previously cited studies, the results from this study suggest there may be a connection between hexanol, SS, and SBD incidence.

Although a study explicitly investigating these relationships would need to be conducted to confirm any physiological connections, MdAAT1 may be a good target to further study SS and SBD incidence. Markers at or near this gene may be better targets for developing selectable markers for implementing MAB compared to SNPs simply delimiting the HDI haplotype region in this study regardless of their physical locations.

It should be noted that the LG2 QTL for hexanol in the Dunemann et al. study (2009) only segregated in 'Discovery,' which does not have the HDI haplotype, but not in 'Prima,' which does have the HDI haplotype. Both parents did segregate for iso-pentanol and various esters at this QTL, indicating that independent mutations of MdAAT1 might have occurred that each led to reduced expression of the gene and thereby to increased levels of various alcohols.

\section{Haplotype analyses at LG2 QTL}

A single IBS haplotype at the LG2 QTL, named the HDI haplotype, was associated with increased incidences of SS and SBD in three large families that segregate for one and two copies of the HDI haplotype (Fig. 1). A general trend of negative partial dominance with the HDI haplotype at the LG2 QTL was observed where individuals with each additional copy of the HDI haplotype tended to have higher disorder incidences. This trend was common across all families and across the entire germplasm set (Fig. 4) in both years evaluated. These findings could explain previous reports of moderate SS and/or SBD development in 'Golden Delicious,' 'Grimes Golden,' and 'Rome Beauty' (Harley and Fisher 1931; Brooks and Harley 1934; Plagge and Maney 1937) which all have one copy of the HDI haplotype and were common sources of the HDI haplotype in many of the parents of the families evaluated in this study (Table S4). Indeed, all parents evaluated in this study that had the HDI haplotype inherited this haplotype from 'Grimes Golden,' 'Northern Spy,' 'Fireside,' or 'Rome Beauty' (Table S4). Other sources of this 
haplotype may exist, but since the RosBREED germplasm set was designed to include the most important breeding parents currently represented in the UMN, Washington State University, and Cornell University apple breeding efforts (Peace et al. 2014), the founder genotypes identified in this study should be the most relevant to these US breeding programs. We were unable to connect the pedigrees of these founding sources of the HDI haplotype, but a dose effect was consistently observed regardless of the source of the HDI haplotype, suggesting that the haplotype has a consistent effect on SS and SBD incidence in different genetic backgrounds. These findings, coupled with the identification of other common haplotypes at the LG2 QTL (Table S4), should make implementation of selectable markers for MAB easier and more transferable across different families.

\section{Haplotype analyses at the LG16 QTL}

The variability in disorder incidences between years for some of the compound LG2/LG16 genotypes hampered an unequivocal assessment of haplotype effects. In this study, we propose to classify haplotypes based on their highest observed incidence. For the non- 'Honeycrisp' haplotypes of the three families that segregated for one or two copies of the LG2-HDI haplotype, LG16-H03 $3_{\text {Fireside }}$ was the only haplotype that consistently had no incidence-increasing effect. LG-H06 might be associated with an intermediate effect, while the other four haplotypes ( $\mathrm{H}_{03} 3_{\text {Monark }}, \mathrm{H} 04, \mathrm{H} 07$, and $\mathrm{H} 08$ ) were associated with similar and larger increases.

\section{The interaction between the LG2 and LG16 QTL}

The variability in incidences between years for some of the compound LG2/LG16 genotypes also hampered conclusions on the interplay between the two QTL. The data from the 'Honeycrisp' x MN1702 family suggested LG2 to be epistatic over LG16, as LG16-H07 increased disorder incidence only in the presence of a double dose of LG2-HDI. Such an epistatic pattern was also observed for one of the haplotypes of the two other larger families, but it was not reproducible across years. Consequently, it cannot be excluded that the consistent pattern observed in the 'Honeycrisp' x MN1702 family was coincidental. Examination of additional years and additional families will be needed for definitive conclusions on the (in)dependent action of these two QTL and the exact effects of haplotypes underlying the LG16 QTL.

The reason for the observed opposite effects of the IBS haplotypes shared by MN1702 and 'Monark' is unknown. One explanation is that the uncertainty in the exact position of this QTL (Table 2) could have led to the incorrect position being examined. An analysis of the phased marker data revealed that the IBS haplotypes shared between MN1702 and 'Monark' at this QTL extend from 34.21 to $38.68 \mathrm{cM}$, which does not cover every peak identified for this QTL (Table 2). The haplotypes are also possibly not IBD whereby their corresponding homologs might have sequence polymorphism that remained hidden with the current set of SNP markers. Regardless of the position and origin of LG16 haplotypes, effects of haplotypes at the LG2 QTL are much more consistent across years and the germplasm evaluated, making it a better marker-assisted breeding target.

Another point of consideration regarding the QTL on LG16 is that LG13 is the homoeologous chromosome from the most recent genome duplication that occurred in apple (Velasco et al. 2010), and a QTL for SS was found on LG13 in roughly the same physical position as the LG16 QTL. The LG13 QTL was only present in 2014 and with a lower Bayes factor than the LG2 and LG16 QTLs, but it could be another genetic factor in SS and SBD incidence that could not be fully identified and characterized in this study, possibly due to limitations of the families evaluated, population sizes, and/or the type of phenotyping utilized.

\section{SS and SBD variation due to additional causes}

A moderate percentage of individuals that have haplotypes associated with higher disorder incidences at these QTL have low or even no incidence of either disorder. This observation was not unexpected, considering how many previous studies evaluating SS and SBD in 'Honeycrisp,' which is considered highly susceptible to both disorders, often observed only small percentage of fruit develop either disorder (Tong et al. 2003, DeLong et al. 2004, 2006; Moran et al. 2009, 2010; DeEll and EhsaniMoghaddam 2010; Ehsani-Moghaddam and DeEll 2013). Some of the discrepancy between observed and expected disorder incidences when considering individual haplotype composition at the identified QTL can be attributed to experimental variation as reflected by non-systematic differences in disorder incidences between 2014 and 2015. A small number of genetically susceptible individuals expressed high disorder incidence in one year but not the other. Evidence of possible genotype-by-year interactions can also be seen in the difference in mean disorder incidence between years in individuals from the 'Honeycrisp' $x$ 'Monark' family that have one copy of the HDI haplotype at the LG2 QTL and the LG16-H03 haplotype at the LG16 QTL, as well as in various haplotype combinations in the 'Honeycrisp' $x$ 'Jonafree' family (Fig. 4). Genotype-by-location effects could also explain some of this discrepancy. This would be similar to previous reports of orchard location and year having an effect on soft scald incidence in 'Honeycrisp' fruit (Tong et al. 2003; Moran et al. 2010).

Another explanation could be that some individuals were not harvested at the ideal maturity level for development of either disorder due to difficulties in estimating fruit maturity of all fruit on a tree based on few or a single fruit destructively sampled at harvest. Immature harvested fruit might not have developed the disorders despite having the genetic predisposition to do so, as 
higher incidences of SS has been reported in apple fruit harvested at more advanced maturities (Harley and Fisher 1931; Brooks and Harley 1934; Meheriuk et al. 1994; Prange et al. 2011). Two studies have reported a point of maturity for "maximum susceptibility," where fruit harvested very late are also less likely to develop SS (Tomkins 1966; Prange et al. 2011). We attempted to harvest fruit at an intermediately advanced maturity based on SI ratings (Blanpied and Silsby 1992) in order to avoid false negative phenotypic values. However, reliably harvesting fruit at the desired SI rating was difficult, resulting in a varied distribution of average SI ratings for fruit at harvest (Fig. S5). Within this distribution, SI rating did not strongly correlate with incidences of SS or SBD in different partitions of the data in this study, including partitions with one versus two copies of the HDI haplotype at the LG2 QTL (Table S3). Additionally, conventional maturity indicators, including SI, have proven to be problematic in estimating maturity of 'Honeycrisp' fruit (Watkins et al. 2005) and perhaps this finding may extend to its offspring. SI rating may also not be an accurate indicator of fruit maturity for individuals in this study or perhaps the SI target used in this study was not an appropriate indicator of a harvest maturity that would maximize expression of SS and SBD formation in individuals that are genetically predisposed to develop these disorders. This explanation is supported by the observation that, though efforts were made generally that ensure only fruit of uniform maturity levels were harvested, occasionally fruit of lower maturity were inadvertently included (possibly due to differences observable only after harvesting and cold storage) and in sets of fruit from individuals where almost all of the fruit had SS or SBD, the fruit that did not develop SS or SBD were clearly less advanced in maturity based on relative background and over-color. These observations could indicate a connection between maturity and SS and SBD incidence that was not captured in this study. It should be noted that the proportion of these less matured fruit was estimated to be less than $1 \%$ of all fruit. Such a low proportion was deemed not to have significantly impacted the identification of major QTL or the effects of haplotypes underlying them.

Some individuals in this study had no copies of the HDI haplotype but developed one or both disorders. Most of these individuals were from two families where one parent was a wild Malus sieversii accession from the USDA Plant Genetic Resources Unit in Geneva, NY. These individuals may have alleles at the LG2 and LG16 QTL that are associated with higher disorder incidences, or different QTL might be segregating in their offspring, but the small sizes of these families may have prohibited the characterization of their alleles and the identification of additional QTL in our study.

\section{Conclusion}

The LG2 QTL is an attractive MAB target given the economic impact of SS and SBD and considering the demonstrated consistent effect of the HDI haplotype across multiple families and years. The HDI haplotype was present in some major breeding parents, including 'Golden Delicious' and 'Honeycrisp' and could be traced back to the founding individuals 'Grimes Golden,' 'Northern Spy,' 'Rome Beauty,' and 'Fireside.' Future research might widen the set of major breeding parents for which the QTL genotypes and associated marker haplotypes are identified.

Selecting against seedlings based on haplotype at the LG2 QTL should be a valuable strategy to develop populations with lower incidences of SS and SBD, though parental contribution at the LG16 should be at least a point of consideration until a better understanding of alleles at the LG16 QTL and their interactions with the HDI haplotype at the LG2 QTL is gained. The best practice to immediately utilize the results in this study for MAB in seedling selection will be to select against the HDI haplotype at the LG2 QTL as the effect of the HDI haplotype was the most clear and consistent trend observed and the highest disorder incidence was consistently observed in individuals that are homozygous for the HDI haplotype.

Acknowledgements This work was partially supported by the USDA National Institute of Food and Agriculture-Specialty Crop Research Initiative projects, "RosBREED: Enabling marker-assisted breeding in Rosaceae" (2009-51181-05808) and "RosBREED: Combining disease resistance with horticultural quality in new rosaceous cultivars" (201451181-22378).

Some genetic data and technical expertise was provided by the FruitBreedomics project: Integrated approach for increasing breeding efficiency in fruit tree crops (www.FruitBreedomics.com), which was cofunded by the EU seventh Framework Programme, project $N^{\circ} 265582$.

We thank David Bedford, Matthew Clark, Emmi Klarer, Sarah Kostick, Ken Mullin, Hannah Hauan, Elizabeth Blissett, and Ashley Powell for assistance in harvesting and phenotyping.

Data archiving statement SNP calls and phenotype data for seedling individuals evaluated in this study can be found in Table S2.

Open Access This article is distributed under the terms of the Creative Commons Attribution 4.0 International License (http:// creativecommons.org/licenses/by/4.0/), which permits unrestricted use, distribution, and reproduction in any medium, provided you give appropriate credit to the original author(s) and the source, provide a link to the Creative Commons license, and indicate if changes were made.

\section{References}

Allard A, Bink MC, Martinez S, Kelner JJ, Legave JM, Di Guardo M et al (2016) Detecting QTLs and putative candidate genes involved in budbreak and flowering time in an apple multiparental population. J Exp Bot 67(9):2875-2888. https://doi.org/10.1093/jxb/erw130

Alspach PA, White AG, Ferguson IB, Volz RK (2000) Genetic variability in apple fruit storage disorders. Acta Hortic 553:241-244

Bianco L, Cestaro A, Sargent DJ, Banchi E, Derdak S, Di Guardo M, Salvi S, Jansen J, Viola R, Gut I, Laurens F, Chagné D, Velasco R, van de Weg E, Troggio M (2014) Development and validation of a 20K single nucleotide polymorphism (SNP) whole genome 
genotyping array for apple (Malus $\times$ domestica Borkh). PLoS One 9(10):e110377. https://doi.org/10.1371/journal.pone.0110377

Bianco L, Cestaro A, Linsmith G, Muranty H, Denancé C, Théron A, Poncet C, Micheletti D, Kerschbamer E, di Pierro EA, Larger S, Pindo M, van de Weg E, Davassi A, Laurens F, Velasco R, Durel CE, Troggio M (2016) Development and validation of the Axiom ${ }^{\circledR}$ Apple 480K SNP genotyping array. Plant J 86(1):62-74. https://doi. org/10.1111/tpj.13145

Bink MC, Uimari P, Sillanpää M, Janss L, Jansen R (2002) Multiple QTL mapping in related plant populations via a pedigree-analysis approach. Theor Appl Genet 104(5):751-762. https://doi.org/10. 1007/s00122-001-0796-x

Bink MC, Boer MP, Ter Braak CJ, Jansen J, Voorrips RE, Van de Weg WE (2008) Bayesian analysis of complex traits in pedigreed plant populations. Euphytica 161(1-2):85-96. https://doi.org/10.1007/ s10681-007-9516-1

Bink MC, Totir LR, ter Braak CJ, Winkler CR, Boer MP, Smith OS (2012) QTL linkage analysis of connected populations using ancestral marker and pedigree information. Theor Appl Genet 124(6): 1097-1113. https://doi.org/10.1007/s00122-011-1772-8

Bink MC, Jansen J, Madduri M, Voorrips RE, Durel CE, Kouassi AB, Laurens F, Mathis F, Gessler C, Gobbin D, Rezzonico F, Patocchi A, Kellerhals M, Boudichevskaia A, Dunemann F, Peil A, Nowicka A, Lata B, Stankiewicz-Kosyl M, Jeziorek K, Pitera E, Soska A, Tomala K, Evans KM, Fernández-Fernández F, Guerra W, Korbin M, Keller S, Lewandowski M, Plocharski W, Rutkowski K, Zurawicz E, Costa F, Sansavini S, Tartarini S, Komjanc M, Mott D, Antofie A, Lateur M, Rondia A, Gianfranceschi L, van de Weg WE (2014) Bayesian QTL analyses using pedigreed families of an outcrossing species, with application to fruit firmness in apple. Theor Appl Genet 127(5):1073-1090. https://doi.org/10.1007/ s00122-014-2281-3

Blanpied GD, Silsby KJ (1992) Predicting harvest date windows for apples. Cornell Cooperative Extension

Brooks C, Harley CP (1934) Soft scald and soggy break-down of apples. J Agr Res 49(1):55-69

Chagné D, Crowhurst RN, Troggio M, Davey MW, Gilmore B, Lawley C, Vanderzande S, Hellens RP, Kumar S, Cestaro A, Velasco R, Main D, Rees JD, Iezzoni A, Mockler T, Wilhelm L, van de Weg E, Gardiner SE, Bassil N, Peace C (2012) Genome-wide SNP detection, validation, and development of an $8 \mathrm{~K}$ SNP array for apple. PLoS One 7(2):e31745. https://doi.org/10.1371/journal.pone. 0031745

Clark MD, Bus VG, Luby JJ, Bradeen JM (2014a) Characterization of the defence response to Venturia inaequalis in 'Honeycrisp' apple, its ancestors, and progeny. Eur J Plant Pathol 140(1):69-81. https://doi. org/10.1007/s10658-014-0444-3

Clark MD, Schmitz CA, Rosyara UR, Luby JJ, Bradeen JM (2014b) A consensus 'Honeycrisp' apple (Malus $\times$ domestica) genetic linkage map from three full-sib progeny populations. Tree Genet Genomes 10(3):627-639. https://doi.org/10.1007/s11295-014-0709-1

Crosby JA, Janick J, Pecknold PC, Korban SS, O'Connor PA, Ries SM, Goffreda J, Voordeckers A (1990) Breeding apples for scab resistance: 1945-1990. Fruit Breed Genet 317:43-70

Daccord N, Celton JM, Linsmith G, Becker C, Choisne N, Schijlen E, van de Geest H, Bianco L, Muranty H, Micheletti D, Di Pierro EA, Gouzy J, Gaillard S, Velasco R, Durel CE, Rees DJG, Laurens F, Lespinasse Y, Quesneville H, Aubourg S, Weigel D, van de Weg E, Troggio M, Bucher E (2017) The apple genome: evolution and methylome dynamics of early fruit development. Nat Genet 49(7): 1099-1106. https://doi.org/10.1038/ng.3886

Dayton DF, Mowry JB, Williams EB, Janick J, Emerson FH, Hough LF, Bailey C (1979) 'Jonafree' apple. Hortscience 14(4):551-552

DeEll JR, Ehsani-Moghaddam B (2010) Preharvest 1methylcyclopropene treatment reduces soft scald in 'Honeycrisp' apples during storage. Hortscience 45(3):414-417
DeLong JM, Prange RK, Harrison PA (2004) The influence of prestorage delayed cooling on quality and disorder incidence in 'Honeycrisp' apple fruit. Postharvest Biol Technol 33(2):175-180. https://doi.org/10.1016/j.postharvbio.2004.02.009

Delong MJ, Prange KR, Harrison AP, Embree GC, Nichols SD, Harrison Wright A (2006) The influence of crop-load, delayed cooling and storage atmosphere on post-storage quality of 'Honeycrisp' apples. J Hortic Sci Biotechnol 81(3):391-396. https://doi.org/10.1080/ 14620316.2006.11512078

Di Guardo M, Bink MC, Guerra W, Letschka T, Lozano L, Busatto N et al (2017) Deciphering the genetic control of fruit texture in apple by multiple family-based analysis and genome-wide association. J Exp Bot 68(7):1451-1466. https://doi.org/10.1093/jxb/erx017

Dunemann F, Ulrich D, Boudichevskaia A, Grafe C, Weber WE (2009) QTL mapping of aroma compounds analysed by headspace solidphase microextraction gas chromatography in the apple progeny 'Discovery' $\times$ 'Prima'. Mol Breed 23(3):501-521. https://doi.org/ 10.1007/s11032-008-9252-9

Durand JB, Allard A, Guitton B, Ban de Wg EW, Bink MC, Costes E (2017) Predicting flowering behavior and exploring its genetic determinism in an apple multi-family population based on statistical indices and simplified phenotyping. Front Plant Sci 8. https://doi. org/10.3389/fpls.2017.00858

Ehsani-Moghaddam B, DeEll JR (2013) Relationships among postharvest ripening attributes and storage disorders in 'Honeycrisp' apple. Fruits 68(4):323-332. https://doi.org/10.1051/fruits/2013078

Evans K, Guan Y, Luby J, Clark M, Schmitz C, Brown S, Orcheski B, Peace C, van de Weg E, Iezzoni A (2011a) Large-scale standardized phenotyping of apple in RosBREED. Acta Hortic 945:233-238

Evans KM, Patocchi A, Rezzonico F, Mathis F, Durel CE, Fernández-Fernández $\mathrm{F}$, Boudichevskaia A, Dunemann $\mathrm{F}$, Stankiewicz-Kosyl M, Gianfranceschi L, Komjanc M, Lateur M, Madduri M, Noordijk Y, van de Weg WE (2011b) Genotyping of pedigreed apple breeding material with a genome-covering set of SSRs: trueness-to-type of cultivars and their parentages. Mol Breed 28(4):535-547. https:// doi.org/10.1007/s11032-010-9502-5

Fan X, Mattheis JP, Blankenship S (1999) Development of apple superficial scald, soft scald, core flush, and greasiness is reduced by MCP. J Agric Food Chem 47(8):3063-3068. https://doi.org/10.1021/ jf981176b

Farneti B, Di Guardo M, Khomenko I, Cappellin L, Biasioli F, Velasco R, Costa F (2017) Genome-wide association study unravels the genetic control of the apple volatilome and its interplay with fruit texture. J Exp Bot 68(7):1467-1478. https://doi.org/10.1093/jxb/erx018

Fresnedo-Ramírez J, Bink MC, van de Weg E, Famula TR, Crisosto CH, Frett TJ et al (2015) QTL mapping of pomological traits in peach and related species breeding germplasm. Mol Breed 35(8):166. https://doi.org/10.1007/s11032-015-0357-7

Fresnedo-Ramírez J, Frett TJ, Sandefur PJ, Salgado-Rojas A, Clark JR, Gasic K, Peace CP, Anderson N, Hartmann TP, Byrne DH, Bink MC (2016) QTL mapping and breeding value estimation through pedigree-based analysis of fruit size and weight in four diverse peach breeding programs. Tree Genet Genomes 12(2):1-8

Guan Y, Peace C, Rudell D, Verma S, Evans K (2015) QTLs detected for individual sugars and soluble solids content in apple. Mol Breed 35(6):135. https://doi.org/10.1007/s11032-015-0334-1

Harley CP, Fisher DF (1931) A study of the internal atmosphere of apples in relation to soft scald. In Proceedings. J Am Soc Hortic Sci 27: 271-275

Henriod RE, Tustin DS, Breen KC, Oliver M, Dayatilake GA, Palmer JW et al (2008) Thinning effects on 'Scifresh' apple fruit quality at harvest and after storage. Acta Hortic 903: 783-788 
Hopkirk G, Wills RB (1981) Variation in fatty acid composition of apples in relation to soft scald. Phytochemistry 20(2):193-195. https://doi. org/10.1016/0031-9422(81)85091-1

Howard NP, van de Weg E, Bedford DS, Peace CP, Vanderzande S, Clark MD, Teh SL, Cai L, Luby JJ (2017) Elucidation of the 'Honeycrisp' pedigree through haplotype analysis with a multi-family integrated SNP linkage map and a large apple (Malus $\times$ domestica) pedigreeconnected SNP data set. Hortic Res 4:17003. https://doi.org/10. 1038/hortres.2017.3

Johnston J, Lallu N, Brookfield P, Punter M, Pidakala P, Haynes G, et al (2009) Minimising soft scald risk for 'Scifresh' apples. Report to ENZA Limited. Plant and Food Client Report 30873

Johnston J, Brookfield P, Lallu N, Tustin DS, Haynes G, Robertson J, Dayatilake D, Hedderley D, Pidakala P, Billing D, Farrell M (2010) Prediction of disorder risk for 'Scifresh' apples. Report to ENZA Limited. Plant and Food Client Report 38307

Kass RE, Raftery AE (1995) Bayes factors. J Am Stat Assoc 90(430): 773-795. https://doi.org/10.1080/01621459.1995.10476572

Korban SS, Janick J, Williams EB, Emerson FH (1988) 'Dayton' apple. Hortscience 23:927-928

Kumar S, Rowan D, Hunt M, Chagné D, Whitworth C, Souleyre E (2015) Genome-wide scans reveal genetic architecture of apple flavour volatiles. Mol Breed 35(5):1-16

Kupferman, E (2001) Storage scald of apples. Washington State University - Tree Fruit Research and Extension Center

Laurens F, Durel CE, Patocchi A, Peil A, Salvi S, Tartarini S et al (2010) Review on apple genetics and breeding programmes and presentation of a new European initiative to increase fruit breeding efficiency. J Fruit Sci 27:102-107

Leisso RS, Buchanan DA, Lee J, Mattheis JP, Sater C, Hanrahan et al (2015) Chilling-related cell damage of apple (Malus $\times$ domestica Borkh.) fruit cortical tissue impacts antioxidant, lipid and phenolic metabolism. Physiol Plant 153(2):204-220. https://doi.org/10.1111/ ppl.12244

Leisso RS, Gapper NE, Mattheis JP, Sullivan NL, Watkins CB, Giovannoni JJ, Schaffer RJ, Johnston JW, Hanrahan I, Hertog MLATM, Nicolaï BM, Rudell DR (2016) Gene expression and metabolism preceding soft scald, a chilling injury of 'Honeycrisp' apple fruit. BMC Genomics 17(1):798. https://doi.org/10.1186/s12864016-3019-1

Mangandi J, Verma S, Osorio L, Peres NA, van de Weg E, Whitaker VM (2017) Pedigree-based analysis in a multiparental population of octoploid strawberry reveals QTL alleles conferring resistance to Phytophthora cactorum. G3-Genes Genom Genet 7(6):1707-1719

Mann H, Bedford D, Luby J, Vickers Z, Tong C (2005) Relationship of instrumental and sensory texture measurements of fresh and stored apples to cell number and size. Hortscience 40(6):1815-1820

McClure KA, Gardner KM, Toivonen PM, Hampson CR, Song J, Forney CF, DeLong J, Rajcan I, Myles S (2016) QTL analysis of soft scald in two apple populations. Hortic Res 3:16043. https://doi.org/10. 1038/hortres.2016.43

McKay SJ, Bradeen JM, Luby J (2011) Prediction of genotypic values for apple fruit texture traits in a breeding population derived from 'Honeycrisp'. J Am Soc Hortic Sci 136(6):408-414

McLeod AI (2011) Kendall: Kendall rank correlation and Mann-Kendall trend test. R package version 2.2. https://CRAN.R-project.org/ package $=$ Kendall

Meheriuk MP, Prange RK, Lidster RK, Porritt SW (1994) Postharvest disorders of apples and pears. Agriculture and Agri-Food Canada, Ottowa

Mora JRH, Micheletti D, Bink M, Van de Weg E, Bassi D, Nazzicari N, Caprera A, Dettori MT et al (2017) Integrated QTL detection for key breeding traits in multiple peach progenies. BMC Genomics 18(1): 404. https://doi.org/10.1186/s12864-017-3783-6
Moran RE, DeEll JR, Halteman W (2009) Effects of preharvest precipitation, air temperature, and humidity on the occurrence of soft scald in 'Honeycrisp' apples. Hortscience 44(6):1645-1647

Moran RE, DeEll JR, Murr DP (2010) Effects of preconditioning and fruit maturity on the occurrence of soft scald and soggy breakdown in 'Honeycrisp' apples. Hortscience 45(11):1719-1722

Peace CP, Luby JJ, van de Weg WE, Bink MC, Iezzoni AF (2014) A strategy for developing representative germplasm sets for systematic QTL validation, demonstrated for apple, peach, and sweet cherry. Tree Genom Genet 10(6):1679-1694. https://doi.org/10.1007/ s11295-014-0788-z

Plagge HH, Maney TJ (1937) Factors influencing the development of soggy breakdown in apples. J Agric Res 55:739-763

Plagge HH, Maney TJ, Pickett BS (1935) Functional diseases of the apple in storage. Iowa State College of Agriculture and Mechanic Arts, Ames, p 329

Prange R, Delong J, Nichols D, Harrison P (2011) Effect of fruit maturity on the incidence of bitter pit, senescent breakdown, and other postharvest disorders in 'Honeycrisp' apple. J Hortic Sci Biotechnol 86(3):245-248. https://doi.org/10.1080/14620316.2011.11512756

R Core Team (2017) R: a language and environment for statistical computing. R Foundation for Statistical Computing, Vienna, Austria. URL https://www.R-project.org/

Roach JA, Verma S, Peres NA, Jamieson AR, van de Weg WE, Bink MC et al (2016) FaRXf1: a locus conferring resistance to angular leaf spot caused by Xanthomonas fragariae in octoploid strawberry. Theor Appl Genet 129(6):1191-1201. https://doi.org/10.1007/ s00122-016-2695-1

Robinson T, Lopez S (2012) Crop load affects 'Honeycrisp' fruit quality more than nitrogen, potassium, or irrigation. Acta Hortic 940:529 537

Robinson TL, Watkins CB (2003) Cropload of 'Honeycrisp' affects not only fruit size but many quality attributes. NY Fruit Quarterly 11(3): $7-10$

Rom CR, Rom RC, Moore JN, Clark JR (1998) Advanced selections of summer apples from the Arkansas apple breeding program. Hortscience 33(3):531-532

Rosenberger D, Schupp J, Watkins C, Iungerman K, Hoying S, Straub D, Cheng L (2001) 'Honeycrisp': promising profit maker or just another problem child. NY Fruit Q 9(3):9-13

Rosyara UR, Bink MC, van de Weg E, Zhang G, Wang D, Sebolt A et al (2013) Fruit size QTL identification and the prediction of parental QTL genotypes and breeding values in multiple pedigreed populations of sweet cherry. Mol Breed 32(4):875-887. https://doi.org/10. 1007/s11032-013-9916-y

Sandefur P, Oraguzie N, Peace C (2016) A DNA test for routine prediction in breeding of sweet cherry fruit color, Pav-Rf-SSR. Mol Breed 36(3):1-11

Schmitz CA, Clark MD, Luby JJ, Bradeen JM, Guan Y, Evans K, Orcheski B, Brown S, Verma S, Peace C (2013) Fruit texture phenotypes of the RosBREED US apple reference germplasm set. Hortscience 48(3):296-303

Sillanpää MJ, Arjas E (1999) Bayesian mapping of multiple quantitative trait loci from incomplete outbred offspring data. Genetics 151(4): $1605-1619$

Souleyre EJ, Greenwood DR, Friel EN, Karunairetnam S, Newcomb RD (2005) An alcohol acyl transferase from apple (cv. Royal Gala), MpAAT1, produces esters involved in apple fruit flavor. FEBS J 272(12):3132-3144

Souleyre EJ, Chagné D, Chen X, Tomes S, Turner RM, Wang MY et al (2014) The AAT1 locus is critical for the biosynthesis of esters contributing to 'ripe apple' flavour in 'Royal Gala' and 'Granny Smith' apples. Plant J 78(6):903-915. https://doi.org/10.1111/tpj.12518

Stegmeir T, Schuster M, Sebolt A, Rosyara U, Sundin GW, Iezzoni A (2014) Cherry leaf spot resistance in cherry (Prunus) is associated with a quantitative trait locus on linkage group 4 inherited from 
P. canescens. Mol Breed 34(3):927-935. https://doi.org/10.1007/ s11032-014-0086-3

Tomkins RG (1966) Soft scald of Ellison's Orange. Agricultural Research Council Ditton Laboratory Annual Report, 1965/66 11-13

Tong C, Krueger D, Vickers Z, Bedford D, Luby J, El-Shiekh A, Shackel K, Ahmadi H (1999) Comparison of softening-related changes during storage of 'Honeycrisp' apple, its parents, and 'Delicious'. J Am Soc Hortic Sci 124(4):407-415

Tong CB, Bedford DS, Luby JJ, Propsom FM, Beaudry RM, Mattheis JP, Watkins CB, Weis SA (2003) Location and temperature effects on soft scald in 'Honeycrisp' apples. Hortscience 38(6):1153-1155

Trujillo DI, Mann HS, Tong CB (2012) Examination of expansin genes as related to apple fruit crispness. Tree Genet Genomes 8(1):27-38. https://doi.org/10.1007/s11295-011-0417-z

Van de Weg WE, Voorrips RE, Finkers R, Kodde LP, Jansen J, Bink MC (2003) Pedigree genotyping: a new pedigree-based approach of QTL identification and allele mining. Acta Hortic 663:45-50

Velasco R, Zharkikh A, Affourtit J, Dhingra A, Cestaro A, Kalyanaraman A, Fontana P, Bhatnagar SK, Troggio M, Pruss D, Salvi S, Pindo M, Baldi P, Castelletti S, Cavaiuolo M, Coppola G, Costa F, Cova V, Dal Ri A, Goremykin V, Komjanc M, Longhi S, Magnago P, Malacarne G, Malnoy M, Micheletti D, Moretto M, Perazzolli M, Si-Ammour A, Vezzulli S, Zini E, Eldredge G, Fitzgerald LM, Gutin N, Lanchbury J, Macalma T, Mitchell JT, Reid J, Wardell B, Kodira C, Chen Z, Desany B, Niazi F, Palmer M, Koepke T, Jiwan D, Schaeffer S, Krishnan V, Wu C, Chu VT, King ST, Vick J, Tao Q, Mraz A, Stormo A, Stormo K, Bogden R, Ederle D, Stella A, Vecchietti A, Kater MM, Masiero S, Lasserre P, Lespinasse Y, Allan AC, Bus V, Chagné D, Crowhurst RN, Gleave AP, Lavezzo E, Fawcett JA, Proost S, Rouzé P, Sterck L, Toppo S, Lazzari B, Hellens RP, Durel CE, Gutin A, Bumgarner RE, Gardiner SE, Skolnick M, Egholm M, van de Peer Y, Salamini F, Viola R (2010) The genome of the domesticated apple (Malus $\times$ domestica Borkh.) Nat Genet 42(10):833-839. https://doi.org/10.1038/ng.654

Voorrips RE, Bink MC, van de Weg WE (2012) Pedimap: software for the visualization of genetic and phenotypic data in pedigrees. $\mathrm{J}$ Hered 103(6):903-907. https://doi.org/10.1093/jhered/ess060
Voorrips RE, Bink MCAM, Kruisselbrink JW, Koehorst- van Putten HJJ, van de Weg WE (2016) PediHaplotyper: software for consistent assignment of marker haplotypes in pedigrees. Mol Breed 36(8): 119. https://doi.org/10.1007/s11032-016-0539-y

Watkins CB, Nock JF (2012) Controlled-atmosphere storage of 'Honeycrisp' apples. Hortscience 47(7):886-892

Watkins CB, Rosenberger DA (2012) Honeycrisp - some preliminary observations. Cornell Fruit Handling and Storage Newsletter

Watkins CB, Nock JF, Weis SA, Jayanty S, Beaudry RM (2004) Storage temperature, diphenylamine, and pre-storage delay effects on soft scald, soggy breakdown and bitter pit of 'Honeycrisp' apples. Postharvest Biol Technol 32(2):213-221. https://doi.org/10.1016/j. postharvbio.2003.11.003

Watkins CB, Erkan M, Nock JF, Iungerman KA, Beaudry RM, Moran RE (2005) Harvest date effects on maturity, quality, and storage disorders of 'Honeycrisp' apples. Hortscience 40(1):164-169

Whitaker VM (2011) Applications of molecular markers in strawberry. J Berry Res 1(3): 115-127

Wills RB (1972) Effect of hexyl compounds on soft scald of apples. Phytochemistry 11(6):1945-1946. https://doi.org/10.1016/S00319422(00)90156-0

Wills RB (1973) Relationship between hexanol levels in apples and the development of soft scald. J Hortic Sci 48(2):165-168. https://doi. org/10.1080/00221589.1973.11514516

Wills RB, Scott KJ (1970) Hexanol and hexyl acetate and soft scald of apples. Phytochemistry 9(5):1035-1036. https://doi.org/10.1016/ S0031-9422(00)85223-1

Yauk YK, Chagné D, Tomes S, Matich AJ, Wang MY, Chen X, Maddumage R, Hunt MB, Rowan DD, Atkinson RG (2015) The O-methyltransferase gene MdoOMT1 is required for biosynthesis of methylated phenylpropenes in ripe apple fruit. Plant J 82(6):937950. https://doi.org/10.1111/tpj.12861

Zhang Z, Schwartz S, Wagner L, Miller W (2000) A greedy algorithm for aligning DNA sequences. J Comput Biol 7(1-2):203-214. https:// doi.org/10.1089/10665270050081478 